\title{
A Multiethnic Perception through the Eyes of Students
}

\author{
Jasmine A. Mutang, Chua B. Seok, Lailawati Madlan, Aminuddin I. Lastar, Shamsul A. Baharuddin, \\ and Asong Joseph
}

\begin{abstract}
Malaysia is a country with diverse races and cultures, particularly in Sabah and Sarawak. Racial harmony in this country is admired by other countries. What so ever, the racial diversity in this country needs high tolerance practices in order to maintain the harmonious under one roof. On the contrary, there is no doubt that behind this harmony exists prejudice, stereotyping, and discrimination that may be ambiguous. Therefore, this study attempts to identify the kind of prejudice, stereotype and discrimination that may be experienced by the five major ethnic in Sabah. Indigenous psychology approach was used in collecting the data. Overall, this study confirms the existence of prejudice and stereotype between ethnic but not at an alarming level. The findings will be discussed further in this paper.
\end{abstract}

Index Terms-Discrimination, prejudice, racial harmony, stereotypes.

\section{INTRODUCTION}

Malaysia is a multiracial country comprises of various majority and minority ethnic. Though, most countries are now moving towards a plural society which due to migration, intermarriage and local ethnic diversity in the country itself, Malaysia is growing strong with its multiracial identity. To ensure that this nation is endure politically and socially stable, peaceful, and harmonious, the multi-ethnic people of Malaysia must have high tolerance rate to live together with. This is because in addition to ethnic diversity, Malaysians have different religion, culture, language and way of life. Unity between different ethnic is important for economic, social, and political stability in Malaysia [1].

In order to ensure that this country persists its strength and harmony, the Prime Minister has emphasized the concept of One Malaysia as a model to unite Malaysians and cultivate the spirit of tolerance among its multiethnic. Since the country's education system has experienced segregation, particularly in the days of British rule when the entry of people from China and India were made possible into this country, the Malay, Chinese and Tamil schools were introduced to adapt these three major ethnic diversity of the British rule at that time[2]. Until now the education system

Manuscript received August 1, 2013; revised November 18, 2013. This work was supported in part by the Ministry of Education Malaysia under the Long Term Research Grant Scheme (Project 4: Sub-project C).

Jasmine A. Mutang, Chua B. Seok, Lailawati Madlan, Aminuddin I. Lastar, and Asong Joseph are with the School of Psychology and Social Work, Universiti Malaysia Sabah, 88400 Kota Kinabalu, Sabah (e-mail: jasmine@ums.edu.my, chuabs@ums.edu.my, lailawati@ums.edu.my, Lastar_ai@yahoo.co.uk and song.aj24@gmail.com).

Shamsul A. Baharuddin is with Universiti Kebangsaan Malaysia, 43600 UKM Bangi Selangor, Malaysia (e-mail: shamsul_ab@yahoo.com). based on ethnicity is still exists. Besides the national school, there are also vernacular schools such as Chinese national-type schools, and Tamil schools in this country. The Chinese and Tamil schools in Malaysia are Malaysian government-aided schools that use Mandarin and Tamil language respectively as the medium of instruction. This indirectly cause of ethnic interaction with other students is limited and less as they just hang out with school friends who come from the same ethnic background [3].

However in the context of Sabah and Sarawak, the scenario is different. Sabah's ethnic diversity does not result in a particular school based on ethnicity except for Chinese vernacular schools. Students from various ethnic and religions enroll in the same National School, Chinese vernacular schools or Christian missionary schools. Consequently, the interaction with other ethnic classmates is unlimited. Still, there are also schools with only one or two ethnic groups due to the influence of demographic factors which only certain ethnic groups inhabit a particular area such as in rural areas. This condition causes them to have limited interaction with other ethnic groups.

Contrariwise, this situation will change as they continue their studies at the university. In the university, they will meet and socialize with students from different ethnic background, language, culture and way of life. Some of them may have had personal experience mixing with other ethnic groups or have heard about other ethnic groups from family, friends, the media and other sources. Since the Malaysian Government has established the New Economic Policy (NEP) after May 13, 1969 incident, which resulted in an introduction of a quota system in admission of students into the university to ensure a balanced ethnic composition of the population in terms of the distribution of students by faculty [4], yet racial polarization is very prevalent in the Malaysian education system. So, it is not unusual for students who come the same ethnic background make up their own group [5]. Therefore, this study aims to identify if there is ethnicity prejudice, stereotyping, and discrimination among university students in the state of Sabah.

\section{STEREOTYPe, PreJUdice, AND ETHNIC DISCRIMINATION}

The study of ethnic relations among university students in Malaysia reported that, the ethnic relations among university students are at a moderate level [6]. The students understand the need for harmonious ethnic relations between ethnic groups in Malaysia. Several other studies have also found that the level of inter-ethnic tolerance is at a moderate level [7]. This situation was attributed by the activities in the university that has helped in creating awareness and motivating students to interact with other ethnic groups. One 
of the most important contributions is the introduction of the Ethnic Relations Module as a mandatory course for all public universities, starting in 2005/2006 [8].

Although there are still ethnic polarizations, but it was found that the gap is decreasing due to lifestyle factors and current norms shared by every individual to pursue a particular interest, social status and material, irrespective of political and ethnic differences [9]. It is undeniable that attitudes towards other ethnic prejudice exist even though not explicitly. Many Malaysians actually are prejudiced and harbor negative stereotypes of others without realizing it[10].

Ethnic prejudice occurs when a certain ethnic group has negative view towards the other ethnic groups [11]. Study [12] found that $80 \%$ of respondents agree that they still have negative prejudices against other ethnic groups. Although on the surface, the relationships between different ethnic looks good, students find it difficult to spend time together for social activities such as having meals together, learning as a group, and more significant is they do not willing to share accommodation as a roommate or housemate together with other ethnic groups.

Stereotypical attitudes occur when one ethnic group to look down on other ethnic groups and thus limiting the interaction between ethnicity and racism poses a thickened [13]. It is irrefutable that every ethnic group would have their stereotypical views of other ethnic groups. For example, ethnic Malays have stereotypes against Chinese and Indians, and vice versa [13]. A study [11] also found that the effects of stereotype may continue from generation to generation that will affect the relationships between the dominant and minority groups.

Discrimination is view as, thoughts and negative beliefs of a person or ethnic group against other ethnic group members or others who influence the behavior of the negative view. It is a manifestation of the prejudice that exists among certain ethnic groups [1]. At this point, the discrimination can be translated to specific groups in the form of acts and words that implied or expressed.

Therefore, this study assesses the understanding of the concept of stereotyping, prejudice and discrimination among students based on the five major ethnic in Sabah (Kadazandusun, Bajau, Chinese, Murut, and Brunei Malay) by asking how they perceive their own ethnic and other ethnic groups.

\section{OBJECTIVE}

The objective of this study is to identify stereotype, prejudice, and discrimination among university students in Sabah, Malaysia by determining how they perceive their own ethnic and other ethnic groups.

\section{METHODOLOGY}

\section{A. Research Design}

This study employed semi-structured interview method to explore the understanding of stereotype, prejudice and discrimination concept among the five major ethnics in Sabah.

\section{B. Samples and Location}

A total of 42 university students in Sabah, Malaysia participated in this study. Eight people from each of the five major ethnic (Kadazandusun, Bajau, Chinese, Murut, and Brunei Malay) in Sabah were involved. Data were collected using in depth interview method regarding their perceptions of their own ethnic and other ethnic groups.

\section{Data Analysis}

Data were analyzed using an indigenous psychology approach through categorization, open coding and axial coding in providing theme analysis proposed by Braun and Clarke (2006) [14].

\section{RESUlTS AND DisCUSSIONS}

\section{A. Ethnics' Perception towards Their Ethnic and Other Ethnics}

How do students from particular ethnic groups perceive themselves and other ethnics? Content analysis results indicated that, it may be two main aspects namely behavior and character as well as the cultural and traditional practiced by an ethnic group. The findings of content analysis on how these four ethnic groups perceive themselves are shown in Fig. 1 to Fig. 10.

\section{B. Kadazandusun}

\section{1) The Kadazandusuns' perception towards their ethnic}

As in Fig. 1, the Kadazandusun ethnic group stated themselves as an ethnic group with characters such as friendly or sociable, love to drink especially home-made alcohol (tapai, lihing or bahar), helpful, polite, cooperative, diligent, brave but lack of confidence. Examples of common responses are:

"The Dusuns are friendly and helpful people. They are humble, because they do not like to be exalted ..."

"Dusun people like drinking, sometimes other ethnics are invited and must join them in their drinking sessions. Whether it is a good habit or not, I do not know..."

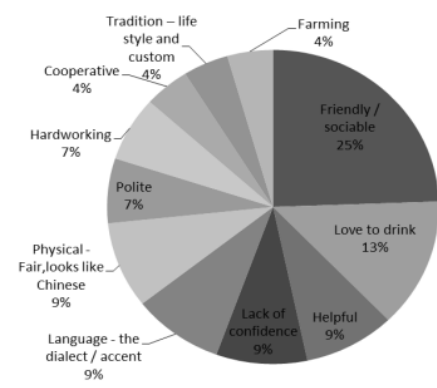

Fig. 1. Kadazandusuns' perception towards their own ethnic.

In cultural and traditional aspects, Kadazandusun is identifiable from their spoken dialect, life styles, and traditional customs. Most of them are identified as farmers. In the relations of looks and physical, the Kadazandusun mentioned that, they have the 'Chinese look' and fair complexion.

2) Other ethnic perception towards the Kadazandusun 
How does other ethnic perceive Kadazandusun ethnic group? The Kadazandusun are seen as a warm and friendly group, hard working and respect others.

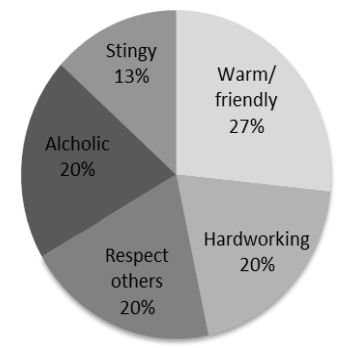

Fig. 2. Other ethnic perception towards the Kadazandusun.

However, the Kadazandusun are also perceived as love to drink alcohol and stingy (Fig. 2). This is may be because of this ethnic has many traditional festivities such as the harvest festival which required them to consume traditional alcohol beverage (tapai, lihing or bahar) and were practiced from generation to generation for the purpose of worshiping the spirit of paddy. The statement which mentioned that they like to drink alcohol is also self-confessed by the Kadazandusuns.

Examples of excerpts from the students' responses are:

"Dusun people are friendly, easy to get along with."

"They respect the religion of others. If I was praying in the room, my roommate (Dusun) immediately turns off the radio".

"... They are physically robust, short, muscular ....."

\section{Bajau}

\section{1) The Bajaus' perception towards their ethnic}

The Bajau ethnic group identifies themselves as has a strong sense of belonging and therefore they seldom mix with other ethnic group, hot-tempered, lazy, too dependent on government aids, and like to gamble. However some of them identified Bajau as friendly.

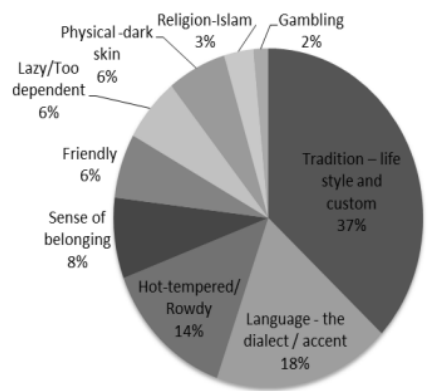

Fig. 3. Bajaus' perception towards their own ethnic.

In terms of culture, tradition, and physical the Bajau can be identified by their religion and origin as almost all of them are Muslim and come from certain areas in Sabah (Kota Belud and Semporna). Other than that, this ethnic group is known by the language spoken (accent and slang) and communication manner, lifestyle, traditional foods, cultural dance, and have dark complexion (Fig. 3). Examples of their responses are:

"When there is dissatisfaction, they will fight ... they are hot-tempered"
"Bajau ... we have dark skin. Majority of them are fishermen”.

\section{2) Other ethnic perception towards the Bajau}

From the perspective of other ethnic groups, the Bajau ethnic group is known as hardworking, friendly, sincere and helpful. Three major perceptions were labeled against ethnic Bajau: 1) rowdy; 2) ill-tempered; and 3) do not like to socialize with others. In addition, they are seen as brave and hardworking (Fig. 4).

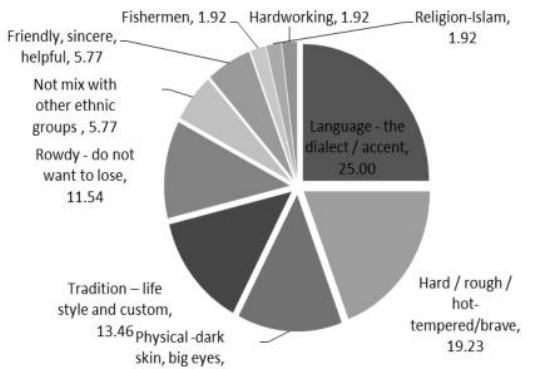

Fig. 4. Other ethnic perception towards the Bajau.

According to other ethnic groups, the Bajaus' can be identified in terms of their language (accent), skin complexion (dark skin color), religion (Islam) and many of them work as fishermen.

\section{Chinese}

\section{1) The local Chinese's perception towards their ethnic}

As in Fig. 5, the Chinese ethnic group disclosed that they are stingy, unfriendly, selfish, less manners, less helpful, but they have hardworking character, open-minded, emphasizing on family values and educated. Most of them are living in the city and doing business. From the physical aspect, generally they have fair complexion and easily identified from the way they speak (accent and slang) and the dialect spoken. Some of the responses are:

"I think we've got a little selfish! I mean, if compared with the natives. They (the natives) more generous."

"Some Chinese people love to act rudely like no manners."

"Chinese people are more concerned with career, education. Delayed marriage would not be a problem."

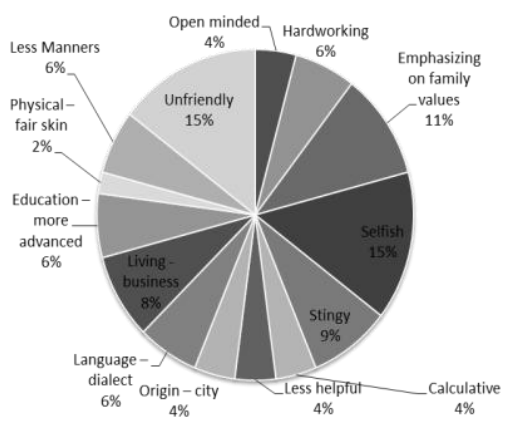

Fig. 5. Chinese's perception towards their ethnic.

\section{2) Other ethnic perception towards the local Chinese}

Other ethnics viewed the Chinese in terms of their behavior and characteristics, language spoken, and physical characteristics. Generally they are seen as hardworking, talkative, punctual, arrogant, stingy, selfish, and do not 
mingle with other ethnics. Some of the statements mentioned by other ethnics were also mentioned by the Chinese (Fig. 6).

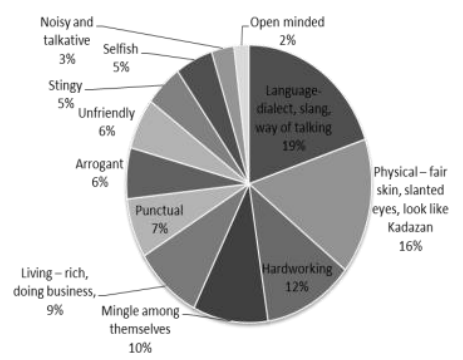

Fig. 6. Other ethnic perception towards the local Chinese.

The Chinese were perceived as open minded and generally rich because most of them are associated with running a business. The Chinese are easily identified by the language they spoke and their pronunciations when speaking the national language. In the aspects of physical appearance, they mostly have fair complexion and small/slanted eyes. Some excerpts of their responses are:

"Sometimes they are not friendly, this is the Chinese people..."

"Most Chinese people are also very hardworking, very... strive hard!

"Chinese people.... they are very punctual. In the aspect of time they are right on time."

\section{E. Murut}

1) The Muruts' perception towards their ethnic

The Muruts identified themselves as an ethnic group who like to drink traditionally made alcohol, respect other ethnic groups, helpful, and sociable. Most of them are from the rural areas. According to them, some are still practicing witchcraft and black magic. However most have embraced Christianity.

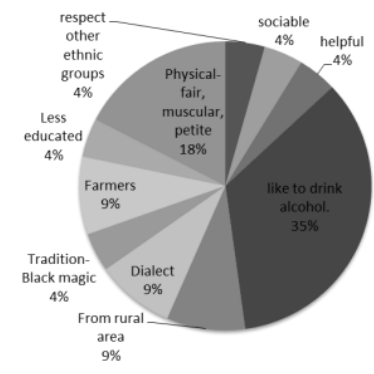

Fig. 7. Muruts' perception towards their own ethnic.

They also expressed that their ethnic group is still relatively backward in terms of education as compared to other major ethics. Most of them are farmers who originated from the rural areas. They can also be identified in terms of the dialect they spoke, and their physical appearance which generally is petite, muscular and have fair complexion (Fig. 7). Parts of their responses are:

"If there are festivals, we must drink. Drink together. For example, at weddings and so on ..."

“Murut people ... we are mostly short, small (laughs).”,

“...still practicing black magic to harm others."

\section{2) Other ethnic perception towards the Muruts}

Not much response was given to the Murut ethnic groups.
This situation may due to this ethnic groups live in areas far away from other ethnic groups in the interior. As in Fig. 8, other ethnics perceived the Muruts as polite and friendly. In terms of physical characteristics, the Muruts are identified as muscular, petite and fair which were also mentioned by the Muruts.

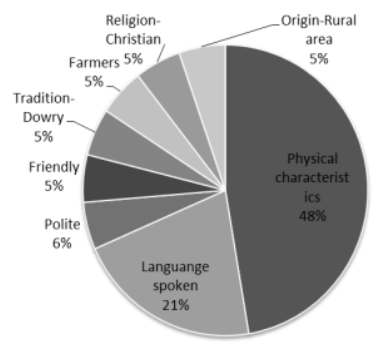

Fig. 8. Other ethnic perception towards the Muruts.

They are associated with the language they spoken, and are famous for their high dowry price. The Muruts are also perceived as originating from the rural areas, farmers, and most are Christians. Below are some of the statements mentioned by other etnics about the Muruts:

“They are similar to the Dusuns', they are friendly ... Murut people are friendly. "

"Their bride price.... dowry is very expensive..."

"They look like the Dusuns', petite, fair,and muscular...because they live in the interior..hilly areas"

\section{F. Brunei Malay (Melayu Brunei)}

1) The Brunei Malays' perception towards their ethnic

The Brunei Malays described themselves as cooperative among their community, respects others especially the elderly, caring and friendly. However, they also mentioned that generally they are talkative, lazy and too choosy when seeking for jobs (Fig. 9).

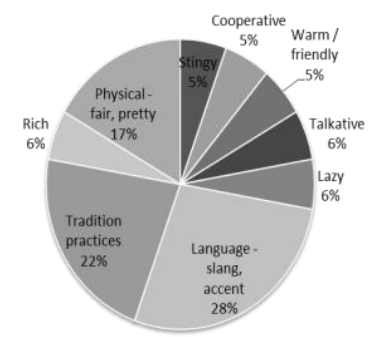

Fig. 9. Brunei Malays' perception towards their own ethnic.

Most of them are associated with their traditional job as fishermen. They can be easily identified by their unique accent and language. They also expressed that most Brunei Malays are tall, have fair complexion, and good looking. Some of the excerpts from the interviews are:

"Our accent, similar to the Malay language but it has Brunei dialects."

"I can recognize him/her by the language he/she has spoken and through her/his name ..Our names (Brunei Malay) is a little different from the other Malay name."

"...like as if there is a commotion...very talkative!"

2) Other ethnic perception towards the Brunei Malays

Not much information provided by other ethnic groups 
against the Brunei Malay. This situation may be due to this ethnic group is not the majority, as ethnic Kadazandusun and Bajau in Sabah. Other ethnics identified the Brunei Malays through their accent, which is easily identified by others. They also perceived as having unique traditional practices. Besides that, the Brunei Malays are also identified by their physical characteristics. Most have fair complexion and according to other ethnics the ladies of Brunei Malays are mostly pretty (Fig. 10).

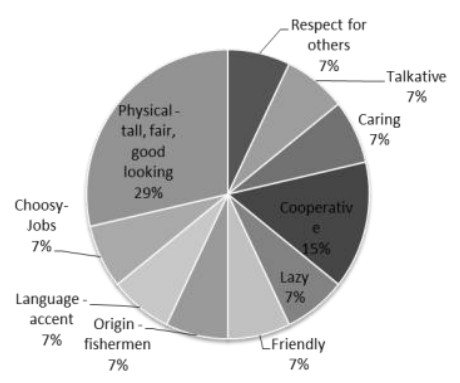

Fig. 10. Other ethnic perception towards the Brunei Malays.

In terms of characteristics, the Brunei Malays are perceived as rich but stingy, cooperative, friendly, lazy and talkative (admitted by the Brunei Malays too). These are some of their statements

"I have three friends are of Brunei Malay ethnic, they all have fair skin."

"Their name is usually Dayang or Awang, because we have a lot of cousins marrying Brunei Malay."

“...lots of money but stingy..."

“...maybe talk a lot, non-stop talking...”

\section{CONCLUSION}

As the whole, it appears that every ethnicity was able expressed their ethnic weakness but could not explain other ethnic groups as well. This may be because of the possible lack of understanding of other ethnic and because of demographic factors that cause less social interactions with other ethnic groups. The majority of students are able to recognize an accent or ethnicity through language spoken and physical appearance.

According to them, generally the Bajau are rough or have violent behavior. Meanwhile Chinese seen as stingy and selfish, while the habit of drinking is associated with the Muruts and Kadazandusuns (also recognized by the Muruts and Kadazandusuns). Brunei Malay is viewed as selfish and lazy. Even so, the Bajau, Murut and Kadazandusun ethnic were viewed positively as warm, friendly and kind. Chinese is seen as open-minded while the Brunei Malays is cooperative.

The findings of this study represent only the views of a handful of students. This study found that students did not provide much information about their personal experiences on the campus of their interaction with other ethnic groups. They say their relationship is good with other ethnic groups.

This may be due to their lack of social interactions with other ethnic groups. Whatsoever, they really do not have negative views of other ethnic or shy about sharing and expressing their real views. Thus, despite of these limitations, the results of this study are expected to provide insight into understanding the concept of prejudice and stereotypes among university students in the state. Future research is expected to explore more fully the concept of prejudice and stereotypes among university students.

\section{ACKNOWLEDGMENT}

This research was supported by The Ministry of Education Malaysia under the Long Term Research Grant Scheme (Project 4: Sub-Project C).

\section{REFERENCES}

[1] A. B. Shamsul and A. Y. Yusoff, "MNging peace in Malaysia: A case study," UKM Ethnic Studies Paper Series, Institute of Ethnic Studies (KITA), Universiti Kebangsaan Malaysia (UKM), Bangi, Malaysia, no. 18, pp. 1-16, 2011.

[2] J. S. Furnivall, Colonail Policy and Pratice, A Comparative of Burma and Netherland India, Cambrige: Cambrige University Press, 1975.

[3] C. C. Lim, "Language choices of Malaysian youth: A case study," Masters dissertation, Faculty of Languages and Linguistics, Universiti Kebangsaan Malaysia, 2008.

[4] V. Selvaratnam, "Ethnicity, inequality and higher education in Malaysian," Comparative Education Review, vol. 32, no. 2, pp. 173-196, 1988.

[5] K. Zainal, D. T. Abu, and Z. Mohamad, "The effect of ethnic relation course on the students perceptions towards ethnic relations among first year student of one public university in Malaysia," Procedia Social and Behavioral Sciences, vol. 2, pp. 3596-3599, 2010.

[6] N. M. Salleh and K. Zainal, "Ethnic relation among the youth in Malaysia: Toward fulfilling the concept of one Malaysia," Procedia Social and Behavioral Sciences, vol. 9, pp. 855-858, 2010.

[7] E. Tamam, F. Idris, W. Y. M. Tien, A. Hamzah, and R. Hamzah, "News media socialization and ethnic tolerance among youth in Malaysia," presented at 15th AMIC Annual Conference Organized by the Asian Media Information And Communication Center, pp. 1-10, 17-20 July 2006.

[8] Z. Hassan, F. Idris, N. A. M. Awal, A. Ya'acob, and M. M. Noor, "Contribution of education to enhancing unity: Malaysian experience," The International Journal of Learning, vol. 17, no. 9, pp. 197-206, 2010.

[9] M. M. Noor, "Social Conflict in Indonesia and Malaysia: Could the Cause be Religious?" Journal kajian Malaysia, vol. 1, no. 1, pp. 188-206, 2001

[10] Z. Samsudin. (2010). Menangani prejudis and stereotaip negatif kaum. [Online]. Available: http://english.cpiasia.net/index.php?option=com _content\&view=article\&id=1848:menangani-prejudis-and-stereotaipnegatif-kaum-\&catid=219: contributors \&Itemid $=171$

[11] J. F. Healey, Race, Ethnicty, Gender and Class : The Sociology of Group Conflict and Change, 5th ed., Newport: Christopher Newport University, pp. 77-87, 2009.

[12] A. S. Hadi, Isu pencapaian Melayu, Kuala Terengganu: Penerbitan UMT, 2003, pp. 19.

[13] M. A. Ibrahim, H. Jamil, and N. M. Yusof, "Prejudis dan Stereotaip Dalam Kalangan Murid Pelbagai Etnik Di Sekolah Manangah Kebangsaan Malaysia," in Proc. the Global Summit on Education, 2013, pp. 1011-1021.

[14] V. Braun and V. Clarke, "Using thematic analysis in psychology," Research in Psychology," vol. 3, no. 2, pp. 77-101, 2006.

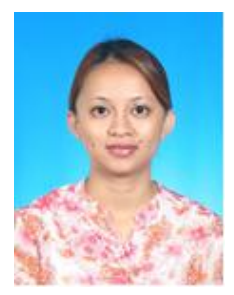

A. M. Jasmine was born in Sarawak, Malaysia on the $29^{\text {th }}$ of July 1980 . She received her college education at Universiti Putra Malaysia (UPM), Malaysia where she studied Human Development (BSc) and Consumer Science (MSc).

She is now attached at the Psychology and Social Health Research Unit under the School of Psychology and Social Work at UMS. She has been involved in a number of psychology related researches in the university. She is planning to obtain her $\mathrm{PhD}$ in the area of Consumer Psychology. 